\title{
BONE MARROW EVALUATION IN PATIENTS WITH PANCYTOPENIA- A CLINICO-HAEMATOLOGICAL STUDY IN A TERTIARY CARE HOSPITAL IN NORTH INDIA
}

\author{
Neetu Purwar1 ${ }^{1}$ Anita Omhare ${ }^{2}$, Mahendra Singh ${ }^{3}$, Dev Prakash Shivhare ${ }^{4}$, Brijendra Nath Tripathi ${ }^{5}$ \\ ${ }^{1}$ Assistant Professor, Department of Pathology, GSVM Medical College, Kanpur, Uttar Pradesh, India. \\ ${ }^{2}$ Assistant Professor, Department of Pathology, GSVM Medical College, Kanpur, Uttar Pradesh, India. \\ ${ }^{3}$ Professor, Department of Pathology, GSVM Medical College, Kanpur, Uttar Pradesh, India. \\ ${ }^{4}$ Assistant Professor, Department of Skin and V. D., GSVM Medical College, Kanpur, Uttar Pradesh, India. \\ ${ }^{5}$ Ex-Professor, Department of Pathology, GSVM Medical College, Kanpur, Uttar Pradesh, India.
}

\section{BACKGROUND}

ABSTRACT

Pancytopenia is relatively common haematological entity. There are only few thorough studies available in both Indian and western literature related to pancytopenia. We conducted this study to evaluate the haematological and bone marrow findings in patients with pancytopenia and the data would be helpful in planning the diagnostic and therapeutic approach. We wanted to study the clinical presentation, causes of pancytopenia and evaluate the cases of pancytopenia by peripheral smear and bone marrow aspiration. We also wanted to determine the aetiology, clinical and haematological features of pancytopenia.

\section{METHODS}

It was a prospective study and was carried out in the Haematology unit, Department of Pathology, GSVM Medical College, Kanpur over a period of 2 years from January 2017 to December 2018. In this period a total of 90 cases of pancytopenia were reported and patients of all age groups were included. Age and sex incidence, clinical examination, haematological findings, bone marrow aspiration findings were evaluated.

\section{RESULTS}

Megaloblastic anaemia (40\%) is the most common cause of pancytopenia followed by hypoplastic/aplastic anaemia (26.6 \%) and haematological malignancies (13.3\%). Maximum number of patients was in the age group of 11-20 yrs. followed by 31-40 yrs. in this study.

\section{CONCLUSIONS}

In India, Vit B12 and folic acid deficiency (nutritional deficiency) is the leading cause of pancytopenia followed by hypoplastic/aplastic anaemia. Detailed primary haematological investigations along with bone marrow aspiration helps to diagnose and rule out various causes of pancytopenia. It also helps in planning further investigations and management.

\section{KEY WORDS}

Bone Marrow Aspiration, Aplastic Anaemia, Megaloblastic Anaemia, Pancytopenia

HOW TO CITE THIS ARTICLE: Purwar N, Omhare A, Singh M, et al. Bone marrow evaluation in patients with pancytopenia- a clinicohaematological study in a tertiary care hospital in North India. J. Evolution Med. Dent. Sci. 2019;8(29):2311-2315, DOI: $10.14260 /$ jemds/2019/507

\section{BACKGROUND}

Many serious and life-threatening illnesses can present as Pancytopenia. They range from megaloblastic anaemia to bone marrow hypoplasia to marrow aplasia and leukaemias which can be fatal sometimes. Pancytopenia is an important clinicohaematological entity which we encountered in our day-today practice. It can show varying trends in its clinical presentation, mode of treatment, and clinical outcome. ${ }^{1}$ In Pancytopenia all three major formed elements of blood (Red blood cells [RBC], white blood cells [WBC] and platelets) are below normal reference limit. ${ }^{2}$

Patients with pancytopenia commonly presents with anaemia or thrombocytopenia. Though leukopenia is not a

'Financial or Other Competing Interest': None.

Submission 15-06-2019, Peer Review 05-07-2019,

Acceptance 09-07-2019, Published 22-07-2019.

Corresponding Author:

Dr. Neetu Purwar,

35/New Type 4,

GSVM Medical College,

Kanpur, Uttar Pradesh, India.

E-mail: neetu.purwar@gmail.com

DOI: $10.14260 /$ jemds/2019/507 common cause of primary presentation, but it can be the life threatening during the course of the disorder. ${ }^{3}$ The causes of pancytopenia in India are still not very well defined in various studies. ${ }^{4,5}$ The present study has been done to evaluate bone marrow findings in patients presenting with pancytopenia, and the results of this study would surely help for diagnostic, prognostic, and therapeutic approach in patients presenting with cytopenia.

\section{METHODS}

This was a cross-sectional comparative study conducted over a period of 2 year (January 2017 to December 2018) in the Haematology unit, department of Pathology, GSVM Medical College, Kanpur. Criteria for diagnosis of pancytopenia were: Haemoglobin less than $10 \mathrm{gm} / \mathrm{dl}$, TLC less than $4000 / \mathrm{mm}^{3}$ and platelet count less than $1,00,000 / \mathrm{mm}^{3}$. Bone marrow aspiration was performed using Salah needle either from posterior iliac crest or sternum, under local anaesthesia, with all aseptic precautions and informed consent. The relevant clinico-haematological parameters were recorded. The bone marrow aspiration smears were stained with Leishman's stain for microscopy and when required special stains such as periodic acid Schiff and myeloperoxidase stain and Perl's stain 
were performed. The causes of pancytopenia were analysed based on various clinico-haematological parameters, which includes complete haemogram, peripheral blood film examination, absolute reticulocyte count, bone marrow aspiration, clinical features, age and gender distribution and compared with the various studies published in literature;

\section{Statistical Analysis}

The data was collected and analysed using standard statistical chi-square test, $\mathrm{P}<0.05$ statistically significant. Data was entered in Microsoft excel and analysis was done using SPSS version 22

\section{RESULTS}

A total of 90 patients who presented with pancytopenia were studied. Incidence of pancytopenia was more in male than female patients with a male-to-female ratio of $1.3: 1$ as shown in Table 1.

The age group of patients in our study presenting with pancytopenia was from 2 to 78 years with mean age, 40 years. Out of total 90 cases, pancytopenia was seen in 32 paediatric patients (2-18 years); and out of 32 paediatric cases 20 were males and 12 were females as shown in Table 1. No familial disease was seen in association with pancytopenia. Most of the patients presented with complaints of generalized weakness, fever and dyspnea and physical examination showing pallor in most of the cases, and hepatosplenomegaly was noted in cases of megaloblastic anaemia, subleukaemic leukaemia, MDS, malaria, storage disorder and kala azar. Bony tenderness was seen in 2 cases of multiple myeloma as well as in 05 cases of subleukaemic leukaemia. Lymphadenopathy was seen in 02 cases of subleukaemic leukaemia -lymphoblastic type. Haematological parameters (Haemoglobin, Total leucocyte count, and Platelets) were lower than the criteria for pancytopenia in all the cases. The predominant blood picture was macrocytic anaemia in 38 cases $(42.2 \%)$ followed by dimorphic anaemia in 32 cases (35.5\%); peripheral smear in patients with megaloblastic anaemia showed macroovalocytes with hyper segmented neutrophils on most of the cases. Normocytic normochromic anaemia was seen in $13.3 \%$ of the cases; and normocytic hypochromic anaemia, in $8.8 \%$ of cases. Leucopenia and thrombocytopenia were seen in all cases but marked thrombocytopenia was noted in 8 cases of subleukaemic leukaemia.

The various causes of pancytopenia in bone marrow aspiration findings which we encountered in our study are shown in Table 2. The most common cause of pancytopenia was megaloblastic anaemia as noted in $40 \%$ of cases, out of which 22 were males and 14 were females, their age group was 4 to 78 years, with a mean age of 41 years. Out of 36 cases of megaloblastic anaemia 6 were showing some neurological deficits, 10 male patients had history of chronic alcohol intake and 2 patients had history of malabsorption syndrome.

\begin{tabular}{|c|c|c|c|c|c|}
\hline Age Group (Years) & Male & $\mathbf{\%}$ & Females & $\mathbf{\%}$ & Total \% \\
\hline $1-10$ & 10 & 11.1 & 02 & 2.2 & 13.3 \\
\hline $11-20$ & 10 & 11.1 & 10 & 11.1 & 22.2 \\
\hline $21-30$ & 04 & 4.4 & 06 & 6.6 & 11.1 \\
\hline $31-40$ & 11 & 12.2 & 06 & 6.6 & 18.8 \\
\hline $41-50$ & 06 & 6.6 & 06 & 6.6 & 13.3 \\
\hline $51-60$ & 04 & 4.4 & 05 & 5.5 & 10.0 \\
\hline$>60$ years & 06 & 6.6 & 04 & 4.4 & 11.1 \\
\hline Total & $\mathbf{5 1}$ & $\mathbf{5 6 . 6 6}$ & $\mathbf{3 9}$ & $\mathbf{4 3 . 3 4}$ & $\mathbf{1 0 0}$ \\
\hline Table 1. Age and Sex Distribution in Pancytopenia Patients \\
\hline
\end{tabular}

\begin{tabular}{|c|c|c|c|}
\hline Sl. No. & Diagnosis & No. of Cases & Percentage \\
\hline 1 & Megaloblastic anaemia & 36 & 40 \\
\hline 2 & Hypoplastic/Aplastic Anaemia & 24 & 26.6 \\
\hline 3 & Acute leukaemia & 12 & 13.3 \\
\hline 4 & Dual deficiency anaemia & 05 & 5.5 \\
\hline 5 & Myelodysplastic syndrome & 04 & 4.4 \\
\hline 6 & Multiple myeloma & 03 & 3.3 \\
\hline 7 & Malaria & 02 & 2.2 \\
\hline 8 & Storage disorders & 01 & 1.1 \\
\hline 9 & Leishmaniasis & 01 & 1.1 \\
\hline 10 & Post viral pancytopenia & 01 & 1.1 \\
\hline 11 & Inconclusive & 01 & 1.1 \\
\hline Total & & $\mathbf{9 0}$ & $\mathbf{1 0 0}$ \\
\hline Table 2. Causes of Pancytopenia Based on Bone Marrow Examination \\
\hline
\end{tabular}

\begin{tabular}{|c|c|c|c|c|c|}
\hline Study & Country & Year & $\begin{array}{c}\text { No. of } \\
\text { Cases }\end{array}$ & $\begin{array}{c}\text { Commonest } \\
\text { Cause }\end{array}$ & $\begin{array}{c}\text { Second most } \\
\text { Common } \\
\text { Cause }\end{array}$ \\
\hline${\text { Kumar et al }{ }^{12}}^{\text {Comdia }}$ & 1999 & 166 & $\begin{array}{c}\text { Hypoplastic } \\
\text { Anaemia (29.15\%) }\end{array}$ & $\begin{array}{c}\text { Megaloblastic } \\
\text { Anaemia (22.3\%) }\end{array}$ \\
\hline${\text { Khodke K et al }{ }^{14}}^{\text {India }}$ & 2001 & 50 & $\begin{array}{c}\text { Megaloblastic } \\
\text { anaemia (44\%) }\end{array}$ & $\begin{array}{c}\text { Hypoplastic } \\
\text { anaemia (14\%) }\end{array}$ \\
\hline${\text { Jha et al }{ }^{13}}^{\text {Gemal }}$ & Nepal & 2007 & 148 & $\begin{array}{c}\text { Hypoplastic } \\
\text { Anaemia (29.05\%) }\end{array}$ & $\begin{array}{c}\text { Megaloblastic } \\
\text { Anaemia (23.64) }\end{array}$ \\
\hline $\begin{array}{c}\text { Gayathri B N } \\
\text { et al }^{1}\end{array}$ & India & 2011 & 104 & $\begin{array}{c}\text { Megaloblastic } \\
\text { anaemia (74.4\%) }\end{array}$ & $\begin{array}{c}\text { Hypoplastic } \\
\text { anaemia (19\%) }\end{array}$ \\
\hline $\begin{array}{c}\text { Pereira A D S } \\
\text { et al }\end{array}$ & India & 2016 & 80 & $\begin{array}{c}\text { Megaloblastic } \\
\text { anaemia (60\%) }\end{array}$ & $\begin{array}{c}\text { Hypoplastic } \\
\text { anaemia (10\%) }\end{array}$ \\
\hline Present study & India & 2019 & 90 & $\begin{array}{c}\text { Megaloblastic } \\
\text { anaemia (40\%) }\end{array}$ & $\begin{array}{c}\text { Hypoplastic } \\
\text { anaemia (26.6\%) }\end{array}$ \\
\hline Table 3. Com
\end{tabular}

Table 3. Common Causes of Pancytopenia Compared to Other Studies

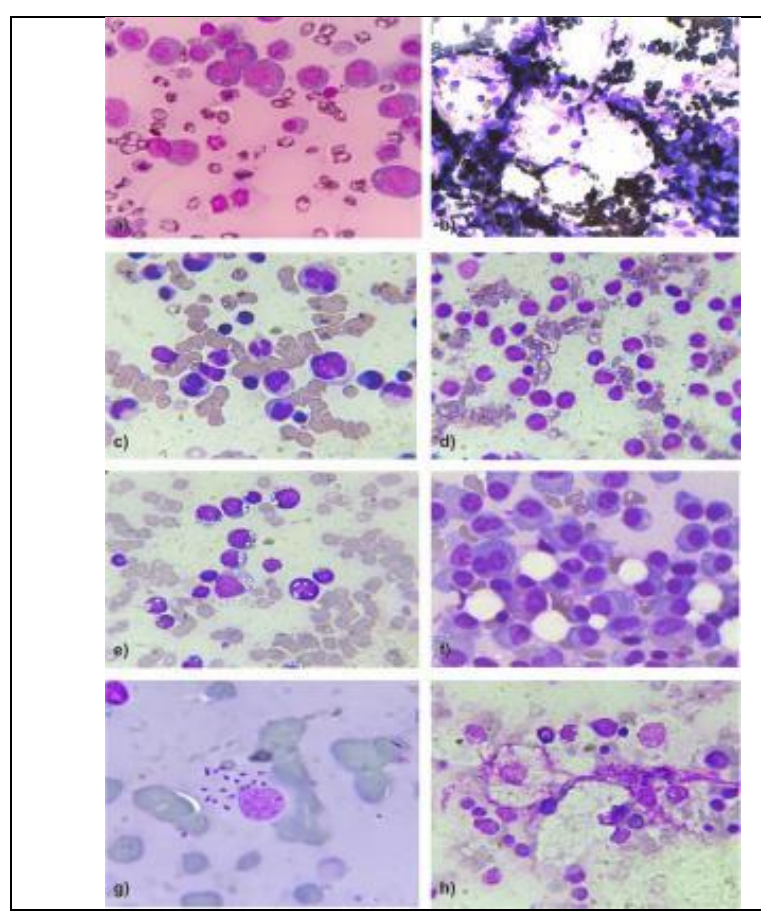

Table 4. Photomicrograph Showing (Leishman Stain $x$ 1000). a) Megaloblastic Maturation of Erythroid Precursors. b) Aplastic Anaemia Showing Markedly Hypocellular Bone Marrow. c) MDSScattered Blast with Changes of Marked Dyserythropoiesis and Dysmyelopoiesis. d) AML-M1 Variant, Bone Marrow Showing more than 50\% Myeloblast. e) ALL -L3 Variant Showing Cytoplasmic Vacuoles. f) Multiple Myeloma Showing Plasma Cells, and Binucleate Forms. g)Leishmaniasis- Showing Intracellular L.D. Bodies. h)Niemann Pick Diseases Showing Large Multivacuolated Histiocytes.

Since estimation of serum Vitamin $\mathrm{B}_{12}$ and folate levels could not be done as a routine process in all the patients, both folic acid and Vitamin $\mathrm{B}_{12}$ were administered to all patients, and they showed complete remission in both clinical symptoms and haematological findings. Bone marrow aspiration findings in all cases showed changes of megaloblastic erythroid hyperplasia, with changes in myeloid series like giant myelocytes and metamyelocytes. Erythroid precursors with Megaloblastic maturation were larger than 
their normal counterparts and showing asynchronous nuclear and cytoplasmic maturation.[Table 4].

Second most common cause of pancytopenia was hypoplastic/ Aplastic anaemia and was noted in 15 males and 9 females; and all the cases were seen in age group of 4 to 60 years, with a mean age of 32 years. In our study, out of 24 cases of aplastic/hypoplastic anaemia, cause of pancytopenia could not be identified in 18 patients and were put in idiopathic cause of hypoplastic/aplastic anaemia. However, in remaining 6 patients of hypoplastic anaemia two patients had history of chronic hepatitis infection. Another patient was on antiepileptic drug treatment. One of the patients had history of hyperthyroidism and was on antithyroid treatment from last 3 years. Two patients had history of autoimmune disorders and was on medication for the same. Bone marrow aspiration was showing changes of hypocellularity with increased fat cells, all the three series in bone marrow (Erythropoiesis, myelopoiesis and megakaryopoiesis) were suppressed with relative increase in lymphocytes and plasma cells.

We encountered subleukaemic leukaemia in 12 cases as a third most common cause of pancytopenia in our study; and their age ranged from 2 to 40 years. Out of total 12 cases, 4 cases were of AML and 8 cases were of ALL. Out of 4 cases of AML we reported 2 cases of AML M2, one case of AML M1 and one case of AML M3. And out of 8 cases of ALL we reported 04 cases of ALL L2, three cases of ALL L1 and one case of ALL L3. In all cases of subleukaemic leukaemia; Bone marrow cellularity was increased in all cases with suppression of Erythroid and megakaryocytic series and normoblastic erythroid maturation. Most of the cells in AML and ALL were myeloblast and lymphoblasts respectively, and comprised of more than $50 \%$ of cells in bone marrow. ALL-L3 variants showing moderate amount of cytoplasm with cytoplasmic vacuoles as shown in Table 4.

We reported $04 \quad(4.4 \%)$ cases of Myelodysplastic syndrome. Peripheral smear shows pancytopenia in all cases with macrocytic anaemia in 2 cases. Peripheral smear also shows pseudo Pelger Huet cells with other changes of dysgranulopoiesis.

Multiple myeloma was diagnosed in 3 cases, who presented with generalised weakness and pain in backbone with bony tenderness. Plasma cell percentage was calculated in conventional Leishman stained bone marrow aspirates, and plasma cells were classified according to cytologic grading of neoplastic cells as mature and those expressing signs of atypia (In differentiation) according to the WHO criteria.

Malarial infestation was seen in 2 cases. Peripheral blood picture showing pancytopenia, and infestation of RBCs with plasmodium vivax in various stages. Bone marrow was mildly hypoplastic with changes of normoblastic erythroid maturation, however bone marrow does not reveal any malarial parasite. On antimalarial treatment patient had complete remission. One case of Niemann-pick disease was diagnosed, in a 5-year-old boy, who had history of fever, weakness and hepatosplenomegaly. Peripheral smear shows increased no of monocytes (12\%). Bone marrow aspirated smears were hypocellular and showing deposition of fair number of foamy large histiocytic cells with peripherally situated relatively small nucleus (Niemann-pick cells) dispersed throughout the smear; and these cells were negative for PAS stain. Hence, we considered Niemann-pick disease as a first diagnosis. There was a single case of leishmaniasis. Bone marrow was markedly hypocellular with increased plasma cell and reticuloendothelial cells. Intracellular L.D. body in a reticulum cell is shown in Table 4. We also got one case of post viral cytopenia in a 35-year male patient. He had a past history of respiratory viral infection. Bone marrow smear reveals increased no of reactive lymphoid cells comprising $32 \%$ of total nucleated cells. In one case of pancytopenia the cause of pancytopenia could not be diagnosed, and bone marrow was mildly hypocellular with no other significant changes.

\section{DISCUSSION}

Pancytopenia is a disease process in which all the three major components of the blood are below normal limit. Pancytopenia develops by various mechanisms which leads to reduction in normal hematopoiesis either due to destruction of bone marrow by toxins and drugs or by suppression of normal marrow growth and differentiation. ${ }^{6}$ In present study, we studied total 90 cases of pancytopenia. Age, sex incidence, various causes of pancytopenia from peripheral smears and bone marrow smears were studied in all cases, and the results were compared with other studies done earlier. Cytopenia in males $(56.6 \%)$ outnumbered than females (43.3\%), with sex (M: F) ratio of 1.3: 1 and the results were compared with studies done by Gayathri BN et al, Tilak and Jain and Kumar et al and they also reported similar incidence. ${ }^{1,4,5}$ In this study, age group of patients with pancytopenia was from 2 to 78 years with a mean age of 40 years. Studies done by Pereira A D S et al and Dias A et al, Tilak and Jain, Tariq et al., reported patients to be in the same age range. ${ }^{4,7,8}$ In our study, we encountered $32(35.5 \%)$ pediatric patients; megaloblastic anaemia was the most common cause for pancytopenia in 15 cases $(46.8 \%)$, followed by acute leukaemias and aplastic anaemia. Similar results were reported by Gayathri B N et al, and Bhatnagar et al.1,9 However, in a study done by Gupta and colleagues, the most common cause of pancytopenia was aplastic anaemia followed by acute leukaemia. ${ }^{10}$ Pancytopenia showed its highest incidence in the age group 11-20 followed by 31-40 years similar to study by Pathak R but not similar to the studies by Pereira A D S et al and Mussarrat et al. They showed highest incidence of pancytopenia in the age grp of 2130 years.7,11,12 Most of the patients presented with complaints of generalized weakness, fever and dyspnea and physical examination showing pallor in most of the cases followed by splenomegaly (37.7\%) and hepatomegaly (22.2\%). Similar results were also noted by Gayathri B N et al. ${ }^{1}$

In various studies conducted worldwide; most common cause of pancytopenia has been aplastic/hypoplastic anaemia. However, megaloblastic anaemia was the most common cause of pancytopenia. This can be due to high prevalence of nutritional deficiency in India and in other developing countries (Table 3).

In our study, incidence of megaloblastic anaemia was 40 $\%$. Incidence of $60 \%$ was reported by Pereria A D S et al, $72 \%$ by Khunger et al. ${ }^{13}$ All the above studies done in India had given stress to the importance of megaloblastic anaemia as the major cause of pancytopenia. It reflects the higher prevalence of nutritional anaemia in Indian subjects. It is a rapidly correctable disorder and should be diagnosed as early as possible. Second common cause of pancytopenia was hypoplastic anaemia (26.6\%) followed by haematological malignancies (13.3\%). Table 3 shows most common and 
second most common cause of pancytopenia compared to other studies.

We encountered $13.3 \%$ incidence of subleukaemic leukaemia, compared to Kumar R et al., they reported incidence of aleukemic leukaemia in $12 \%$ of cases. Jha et al reported acute leukaemia in $19.5 \%$ of the total cases of pancytopenia.5,14 The diagnosis of Acute leukaemia was made on peripheral smear and bone marrow findings, and 4 cases of AML and 8 cases of ALL were reported. Khodke $\mathrm{K}$ et al., reported a single case of AML-M2 in 50 pancytopenic cases. ${ }^{15}$ Kumar $\mathrm{R}$ et al., in their study conducted over a period of 6 years in total 166 cases of pancytopenia encountered 5 cases of ALL, 13 cases of AML and 2 cases of hairy cell leukaemia. ${ }^{5}$

4 cases of MDS were diagnosed from aspiration. Though MDS is second most common cause of pancytopenia in studies by International agranulocytosis and aplastic anaemia group but the frequency was $4.5 \%$ which is nearly similar to our study (4.4\%). Age group for MDS was 35-75 yrs. Though MDS commonly occurs in older age group, less than $10 \%$ of cases can occur below 50 years of age. We did not see any case of MDS in children. ${ }^{11}$ We got 3 (3.3\%) cases of multiple myeloma, compared to Khodke $\mathrm{K}$ et al., who have reported an incidence of $4 \%$ similar to our study however in study done by Tilak $V$ et al. and Khunger JM et al., incidence of multiple myeloma was $1.3 \%$ and $1 \%$ respectively and incidence was slightly lesser than the present study.4,13,15 Other clinical findings (bony tenderness, lytic bone lesions, hypercalcemia, anaemia) were present and increased $M$ protein was also seen in serum protein electrophoresis. We reported 2 (2.2\%) cases of malaria, compared to Tilak V et al., and Kumar R et al., who got an incidence of $3.9 \%$ and $3 \%$ respectively. 4,5 One case of Niemann-pick disease was diagnosed, in a 5-year-old boy. Peripheral smear shows increased no of monocytes (12\%). Bone marrow aspirated smears were hypocellular and showing deposition of fair number of foamy large histiocytic cells which were PAS negative. Hence, we made diagnosis of Niemann-pick disease. Similar results were also noted by Gayathri BN et al but Kumar R et al., and Khunger JM et al. did not encountered any single case of storage disorder as a cause of pancytopenia. ${ }^{1,5,13}$ We also recieved a single case of leishmaniasis $(1.11 \%)$. Pathak $\mathrm{R}$ also reported two cases (1.9\%); but Gayathri BN et al did not reported any case. Kala azar is one of the causes of pancytopenia and frequency is very high in some studies done in India. ${ }^{1,11}$

We also encountered a single case of viral cytopenia, with mildly hypocellular bone marrow and increased reactive lymphocytes in bone marrow. Patient had history of respiratory viral infection one month back, and this could be a case of transient cytopenia, on further follow up patient recovered from cytopenia after 1 and half month. However, study done by Pathak R, Gayathri BN did not report any case.1,11 In present study; bone marrow findings were inconclusive in one case and the cause of pancytopenia could not be diagnosed and bone marrow was mildly hypocellular with no other significant changes. $63.3 \%$ of the patients recovered from pancytopenia. However, in $16.6 \%$ of the cases, patients succumbed to death, which was mainly due to severe pancytopenia and superimposed acute infection due to neutropenia and bleeding due to marked thrombocytopenia mainly in patients of haematological malignancies.

\section{CONCLUSIONS}

We conclude that detailed primary haematological investigations along with bone marrow examination is an important diagnostic tool in hematology which helps to evaluate various causes of pancytopenia and to plan further investigation and management of patients. Post viral cytopenia should always be kept in mind with detailed previous history. Severe cytopenia if not diagnosed on time can affect clinical outcome and prognosis as well.

\section{REFERENCES}

[1] Gayathri BN, Rao KS. Pancytopenia: a clinico haematological study. J Lab Physician 2011;3(1):15-20.

[2] Kar M, Ghosh A. Pancytopenia. Journal Indian Academy of Clinical Medicine 2002;3(1):29-34.

[3] Ishtiaq O, Baqai HZ, Anwer F, et al. Patterns of pancytopenia patients in a general medical ward and a proposed diagnostic approach. J Ayub Med Coll Abbottabad 2004;16(1):8-13. http://www.ayubmed.edu.pk/JAMC/PAST/161/osama.htm-206K-6/24/2007.

[4] Tilak V, Jain R. Pancytopenia - a Clinco-hematologic analysis of 77 cases. Indian J Pathol Microbiol 1999;42(4):399-404.

[5] Kumar R, Kalra SP, Kumar H, et al. Pancytopenia - a six year study. J Assoc Physicians India 2001;49:1078- 81.

[6] Williams MD. Pancytopenia: aplastic anaemia and pure red cell aplasia. In: Lee RG, Foerster J, Lukens J, et al. eds. Wintrobe's Clinical haematology. $10^{\text {th }}$ edn. Williams \& Wilkins 1997: p. 1449-76.

[7] Pereira ADS, Dias A. Haematological analysis of pancytopenia: a prospective study. Int J Sci Stud 2016;4(4):71-8.

[8] Tariq M, Khan NU, Basri R, et al. Aetiology of pancytopenia. Prof Med J 2010;17(2):252-6.

[9] Bhatnagar SK, Chandra J, Narayan S, et al. Pancytopenia in children: etiological profile. J Trop Pediatr 2005;51(4):236-9.

[10] Gupta V, Tripathi S, Tilak V, et al. A study of clinicohaematological profiles of pancytopenia in children. Tropical Doct 2008;38(4):241-3.

[11] Pathak R, Jha A, Sayami G. Evaluation of bone marrow in patients with pancytopenia. Journal of Pathology of Nepal 2012;2(4):265-71.

[12] Mussarrat N, Fazal-e-R, Mohammad TK. Clinical and haematological features of megaloblastic anaemia alone or in combination with iron deficiency anaemia an analysis of 349 patients. J Med Sci 2009;17(2):81-4.

[13] Khunger JM, Arculselvi S, Sharma U, et al. Pancytopenia - a clinic haematological study of 200 cases. Indian J Pathol Microbiol 2002;45(3):375-9.

[14] Jha A, Sayami G, Adhikari RC, et al. Bone marrow examination in cases of pancytopenia. JNMA J Nepal Med Assoc 2008;47(169):12-7.

[15] Khodke K, Marwah S, Buxi G, et al. Bone marrow examination in cases of pancytopenia. J Indian Academy of Clinical Medicine 2001;2:55-9. 